\title{
Factors Associated with Uptake of Contraceptives Among HIV Positive Women on Dolutegravir Based Anti-Retroviral Treatment - A Crossectional Survey in Urban Uganda.
}

Leah Mbabazi ( $\sim$ leahmbabazi@gmail.com )

Infectious Diseases Institute

Mariah Sarah Nabaggala

Infectious Diseases Institute

\section{Suzanne Kiwanuka}

Makerere University College of Health Sciences

Juliet Kiguli

Makerere University College of Health Sciences

Eva Laker

Infectious Diseases Institute

Arthur Kiconco

Makerere University College of Health Sciences

Stephen Okoboi

Infectious Diseases Institute

Mohammed Lamorde

Infectious Diseases Institute

\section{Barbara Castelnuovo}

Infectious Diseases Institute

\section{Research Article}

Keywords: Dolutegravir, Anti-Retroviral Treatment, Contraceptives uptake.

Posted Date: December 20th, 2021

DOI: https://doi.org/10.21203/rs.3.rs-1109814/v1

License: (c) (1) This work is licensed under a Creative Commons Attribution 4.0 International License.

Read Full License 


\section{Abstract \\ Background}

In May 2018, following the preliminary results of a study in Botswana that reported congenital anomalies in babies born to HIV-positive women taking dolutegravir drug, the WHO issued a teratogenicity alert. However, there are scarce data on the impact of this guidance on contraceptive uptake among women taking dolutegravir. We assessed the uptake of contraceptives in HIV-positive women of reproductive age on dolutegravir regimens.

\section{Methods}

We conducted a cross-sectional survey from April 2019 to July 2019 in five government health facilities in central Uganda, where dolutegravir-based regimens were offered as the preferred first-line antiretroviral treatment. We randomly selected 359 non-pregnant women aged 15-49 years taking dolutegravir-based regimens and interviewed them using semi-structured interviewer-administered questionnaires. We collected data on demographics, contraceptive use, individual, social, and health system factors. We described patients' characteristics using descriptive statistics and assessed factors associated with contraceptive uptake using a modified Poisson regression model.

\section{Results}

A total of 359 women were included in the study. The mean age was 37 years (standard deviation=6.8) and overall contraceptive uptake was $38.4 \%$. The most utilized method was injectable method at $58.4 \%$ followed by condoms (15\%), intrauterine device (10.7\%), pills (6.4\%), implants (5.4\%), and sterilization $(0.7 \%)$ Predictors for contraceptive uptake were parity of 3-4 children (Adjusted Prevalence Ratio (APR) $=1.48,95 \%$ confidence interval $(\mathrm{Cl}): 1.14,1.92)$. There was reduced uptake in the age range of $40-49$ years $(A P R=0.45, \mathrm{Cl}: 0.21-0.94)$, unemployed (APR: 0.6, Cl: 0.42- 0.94), women not discussing family planning with their partner (APR $=0.39, \mathrm{Cl}: 0.29-0.52)$ and not receiving family planning counseling $(A P R=0.56, \mathrm{Cl}$ : 0.34-0.92).

\section{Conclusion}

We observed a low-level uptake of contraceptives, with injectables as the most used method. Family planning counseling and partner discussion on family planning were associated with contraceptive uptake among the women who used dolutegravir based regimens. There is a need for more strategies to integrate FP services and increase male involvement in HIV care programs.

\section{Background}


Globally, HIV affects mostly women and girls as they contribute $53 \%$ of the 37.7 million people living with HIV. Sub-Saharan Africa (SSA) accounts for $67 \%$ of the people living with HIV, of which women and girls account for $63 \%$ of all new HIV infections (1). In Uganda, HIV disproportionately affects women, with prevalence at $8.8 \%$ compared to $4.3 \%$ in men, with the highest prevalence in age groups of $35-49$ years (12.9\%) (2). Moreover, women in SSA experience unplanned pregnancies which can contribute to new pediatric HIV infections (3). The public health burden of unintended pregnancies in HIV-positive women is well demonstrated in Uganda; where the prevalence of unplanned pregnancies among women living with HIV was estimated to be $41 \%$ (4). This is a challenge in the elimination of mother-to-child transmission of HIV (eMTCT). Delivery of family planning (FP) services to HIV-positive women remains inadequate because of the parallel nature of FP and HIV services, with an unmet need for contraception of $41.2 \%$ compared to $28 \%$ of the general population (5).

The eMTCT strategy advocates a four-pronged approach: primary prevention of HIV infection among women of childbearing age; prevention of unintended pregnancies among HIV positive women; reduction of MTCT among HIV positive pregnant women by starting or keeping them on effective antiretroviral treatment (ART), care, support; and treatment for HIV positive women and their families (6). Integrating FP into HIV care programs has been an approach to make both FP and HIV care services more accessible to HIV-positive women and couples living with HIV (7).

In 2016, the World Health Organisation (WHO) issued new ART guidelines recommending tenofovir/lamivudine/dolutegravir (TDF/3TC/DTG) as a first-line regimen because of its high efficacy and fewer side-effects compared to the previously used efavirenz based regimen (8). However, a warning was issued by WHO in May 2018, citing a potential risk of neural tube defects in babies born to women who used DTG regimen during pregnancy (9). This concern stemmed from the preliminary analysis of a birth surveillance study in Botswana, which reported 4 cases of neural tube defects out of 426 infants born to women who were on DTG during pregnancy (10).

Therefore, WHO amended the 2016 ART guidelines recommending that women of childbearing age could receive DTG along with consistent and reliable contraception and those who intended to conceive could receive EFV-based ART (11). Following this caution, many countries including Uganda slowed down the transition process and took a conservative approach on women's access to DTG (12). Subsequent data from Tsepamo study in Botswana demonstrated that the risk for neural tube defects was lower than the original report that triggered the teratogenicity alert (13). However, there was still a demand for this to be an opportunity to strengthen FP services for HIV programs.

Currently, there is limited information on the uptake, knowledge, and experiences of the women on FP after switching to DTG based regimens. This study, therefore, aimed to assess the contraceptive uptake and its related factors among HIV-positive women who were receiving DTG based regimens in urban Uganda.

\section{Methods}




\section{Study setting:}

This was a cross-sectional survey conducted from April to July 2019 at the five ART clinics of the Kampala Capital City Authority (KCCA) Uganda, supported by the Infectious Diseases Institute (IDI).

\section{Study population:}

We included HIV-positive women aged 15-49 years receiving DTG based regimens; women who were pregnant were excluded. We estimated the study sample size of 393 using the Kish leslie formula; at 95\% Confidence Interval, Z value of 1.96, 0.05 margin of error and proportion of uptake of FP among HIV positive females $(P)$ as $36 \%(14)$. The number of participants per study site was determined by probability proportionate to size sampling. We then used simple random sampling to select eligible participants for enrolment into the study at each study site.

\section{Data collection:}

The eligible participants were invited to the study sites for data collection via telephone calls. We carried out data collection using semi-structured interviewer-administered questionnaires pretested on five participants who were later not included in the study. All data collection documents were translated into the local language (Luganda). The questionnaires were validated using previous cross-sectional studies that assessed contraceptive uptake in HIV-positive women (14). The questionnaires were cross-checked daily for completeness to ensure quality.

We collected data on the following variables: age in years (stratified as 15-24, 25-29, 30-34, 35-39, 40-44, 45-49), health facility coded as 1, 2, 3, 4 and 5 respectively. Education level (primary, secondary, tertiary, and none), marital status (married, single and cohabiting), employment (employed, unemployed and selfemployed) parity as the number of children (1-2, 3-4, 5-6 and None), religion (Anglican, Catholic, Moslems and others category that included Pentecostal, Jehovah witness, Adventists, Buddhists), desire to have children, sexual activity within the last month, discussion of FP with partner and FP counseling at the facility.

We also collected data on contraceptive use and the type of contraceptives used at that time. We defined modern contraception products or medical procedures that are used to prevent the occurrence of pregnancy such as oral contraceptives, the intra-uterine device (IUD), condoms, progestin-only injections, subdermal implant, vaginal barrier methods, spermicides, emergency contraception, female and male sterilization. We defined traditional contraception methods as withdrawal, abstinence, lactation amenorrhea, fertility awareness methods, rhythm method, and moon beads.

\section{Statistical analysis:}


For data analysis, we used STATA version 14. We used descriptive statistics to describe participants' characteristics and then modified Poisson regression model to identify predictors of uptake of contraception. All independent variables with a $\mathrm{p}$-value $<0.2$ at bivariate analysis and those with biological significance were included in multivariable analysis. Prevalence ratios (PR) were calculated at bivariate and multivariable analysis.

\section{Results}

Three thousand two hundred and seventy-six women (3276) aged 15-49 years had been started or switched to DTG based ART regimen by March 2019. The sampling procedures are shown using the study flow diagram in Figure 1.

\section{Description of Socio-demographic characteristics among respondents}

Participants' characteristics are described in Table 1. Most respondents $(142 ; 39.6 \%)$ belonged to the age category of 40-49 years and the mean age was 37 years (standard deviation (SD):6.8). Half (182, 50.7\%) of the respondents had attained a primary level of education while only $18(5.0 \%)$ had attained a tertiary level of education. Most respondents $(151,42.1 \%)$ were Anglican and the least $(23,6.4 \%)$ were of other religions (Adventists, Buddhists, Pentecostal, Jehovah witness). Most respondents were married (160, $44.6 \%)$ children while $25(7.0 \%)$ had no children.

Most $(269,74.9 \%)$ reported to have received FP counseling at the facility, $245(68.2 \%)$ reported sexual activity in the last one month and 221 (65.6\%) reported they did not want to have any more children. Most respondents $(142,39.6 \%)$, did not discuss family planning methods with their sexual partners. 
Table 1

Characteristics of the respondents and univariate analysis

\begin{tabular}{|c|c|c|c|}
\hline Variable & Category & $\begin{array}{l}\text { Number (column \% } \\
n=359)\end{array}$ & $\begin{array}{l}\text { Contraceptive uptake } \\
\text { count (row \%) }\end{array}$ \\
\hline \multirow[t]{6}{*}{ Facility (code) } & 1 & $153(42.6)$ & Yes No \\
\hline & 2 & $124(34.5)$ & $63(41.2) 90(58.8)$ \\
\hline & 3 & 054(15.0) & $32(25.8) 92(74.2)$ \\
\hline & 4 & 020(05.6) & $30(55.6) 24(44.4)$ \\
\hline & 5 & $008(02.2)$ & $07(35.0) 13(65.0)$ \\
\hline & & & $06(75.0) 02(25.0)$ \\
\hline \multirow[t]{5}{*}{ Age } & $15-24$ & 012(03.4) & 04(33.3) 08(66.7) \\
\hline & $25-29$ & $048(13.4)$ & $30(62.5) 18(37.5)$ \\
\hline & $30-34$ & $064(17.8)$ & $38(59.4) 26(40.6)$ \\
\hline & $35-39$ & 093(25.8) & $39(41.9) 54(58.1)$ \\
\hline & $40-49$ & 142(39.6) & $27(19.0) 115(81.0)$ \\
\hline \multirow[t]{3}{*}{ Education level } & None & 053(14.8) & $12(22.6) 41(77.4)$ \\
\hline & Primary & 182(50.7) & $64(35.2) 118(64.8)$ \\
\hline & Secondary & 124(34.5) & $62(50.0) 62(50.0)$ \\
\hline \multirow[t]{4}{*}{ Religion } & Anglican & $151(42.1)$ & $51(37.8) 100(66.2)$ \\
\hline & Catholic & $123(34.2)$ & $49(39.8) 74(60.2)$ \\
\hline & Moslem & $062(17.3)$ & $23(37.1) 39(62.9)$ \\
\hline & Others & $023(06.4)$ & $15(65.2) 08(34.8)$ \\
\hline \multirow[t]{4}{*}{ Marital status } & Single & $081(22.6)$ & $33(40.7) 48(59.3)$ \\
\hline & Married & $160(44.6)$ & $78(48.8) 82(51.2)$ \\
\hline & Divorced/separated & 078(21.7) & 23(29.5) 55(70.5) \\
\hline & Widow & $040(11.1)$ & $4(10.0) 36(90.0)$ \\
\hline \multirow[t]{4}{*}{ Parity } & $1-2$ & 114(31.7) & $48(42.1) 66(57.9)$ \\
\hline & $3-4$ & $149(41.5)$ & $64(43.0) 85(57.0)$ \\
\hline & $4-6$ & 071(19.8) & 19(26.8) 52(73.2) \\
\hline & None & $025(07.0)$ & $07(28.0) 18(72.0)$ \\
\hline
\end{tabular}

FP: family planning, Facility codes; Kawaala: 1, Kisenyi: 2, Kiswa: 3, Kitebi: 4, Komamboga: 5 


\begin{tabular}{|c|c|c|c|}
\hline Variable & Category & $\begin{array}{l}\text { Number (column \% } \\
\mathrm{n}=359 \text { ) }\end{array}$ & $\begin{array}{l}\text { Contraceptive uptake } \\
\text { count (row \%) }\end{array}$ \\
\hline \multirow[t]{3}{*}{ Employment status } & Unemployed & $077(21.5)$ & 55(49.6) 56(50.4) \\
\hline & formally employed & $111(30.9)$ & $58(33.9)$ 113(66.1) \\
\hline & Self-employed & $171(47.6)$ & $25(32.5) 52(67.5)$ \\
\hline \multirow{2}{*}{$\begin{array}{l}\text { Sexual activity (in last one } \\
\text { month) }\end{array}$} & Yes & $245(68.2)$ & 111(45.3) 134(54.7) \\
\hline & No & 114(31.8) & 27(23.7) 87(76.3) \\
\hline \multirow{3}{*}{$\begin{array}{l}\text { Discussion of FP with } \\
\text { partner }\end{array}$} & Yes & $110(30.6)$ & $85(77.3) 25(22.7)$ \\
\hline & No & 142(39.6) & $33(23.2) 109(76.8)$ \\
\hline & N/A (no partner) & 107(29.8) & $20(18.7) 87(81.3)$ \\
\hline \multirow[t]{2}{*}{ Desire to have children } & Yes & 138(38.4) & $57(49.1) 59(50.9)$ \\
\hline & No & $221(65.6)$ & 81(33.3) 162(66.7) \\
\hline \multirow{2}{*}{$\begin{array}{l}\text { FP Counselling at the } \\
\text { facility }\end{array}$} & Yes & $269(74.9)$ & $124(46.1)$ 145(53.9) \\
\hline & No & 090(25.1) & 14(15.6) 76(84.4) \\
\hline
\end{tabular}

\section{Uptake of contraception}

The majority of women $(221 / 359,61.6 \%)$ were not using any form of contraceptive; only $138 / 359$ $(38.4 \%)$ indicated use of any contraceptive method. Of the 359, 135 (37.9\%) were using modern contraceptives. Figure 2 shows the different FP methods used by the respondents as of the time of the study. The majority $(81 / 138,58.4 \%)$ were using the injectable method. Periodical abstinence, withdrawal, lactation amenorrhea, and sterilization had the least users at $0.7 \%$ each.

Of 221/359 (61.6\%) who did not use contraceptives, 90/221 (40.7\%) cited not being sexually active, $54 / 221$ (24.4\%) feared side effects, 19/221 (8.6\%) anticipated to conceive and 14/22 (6.3\%) their partner did not approve FP use. Some participants gave more than one response. Figure 3 shows the different reasons women gave for not using contraceptives.

\section{Factors associated with uptake of contraceptives}

At multivariable analysis, participants who were in the age category of 40-49 years were less likely to use contraception than those of $15-24$ years (APR $=0.45,95 \% \mathrm{Cl}$ : 0.21-0.94), women who had 3-4 children were 1.5 times more likely to use family planning than those who had $1-2$ children (APR $=1.48,95 \%$ Cl: 1.14 1.92). Unemployed women were less likely to use contraception (APR $=0.63,95 \% \mathrm{Cl}: 0.42-0.94$ ) than the ones who were formally employed. Women who did not discuss FP with their partners (APR $=0.39,95 \% \mathrm{Cl}$ : 
0.29-0.52) were also less likely to use FP, and participants who did not receive FP counseling (APR $=0.56$, 95\% Cl: 0.34-0.92) were less likely to use FP (Table 2).

Table 2

Factors associated with uptake of contraceptives

\begin{tabular}{|c|c|c|c|c|c|}
\hline Variable & Category & $\begin{array}{l}\text { Unadjusted PR } \\
(95 \% \mathrm{Cl})\end{array}$ & $\begin{array}{l}P \\
\text { value }\end{array}$ & $\begin{array}{l}\text { Adjusted PR } \\
\text { (95\% Cl) }\end{array}$ & $\begin{array}{l}P \\
\text { value }\end{array}$ \\
\hline \multirow[t]{6}{*}{ Age } & $15-24$ & 1.00 (ref) & 0.14 & 1.00 (ref) & 0.696 \\
\hline & $25-29$ & $1.88(0.82,4.30)$ & 0.17 & \multirow{2}{*}{$\begin{array}{l}0.87(0.43 \\
1.75)\end{array}$} & 0.570 \\
\hline & $30-34$ & $1.78(0.78,4.07)$ & 0.59 & & 0.333 \\
\hline & $35-39$ & $1.26(0.55,2.90)$ & 0.21 & $\begin{array}{l}0.81(0.39 \\
1.69)\end{array}$ & 0.035 \\
\hline & \multirow[t]{2}{*}{$40-49$} & \multirow[t]{2}{*}{$0.57(0.24,1.36)$} & & \multicolumn{2}{|l|}{$\begin{array}{l}0.71(0.36 \\
1.42)\end{array}$} \\
\hline & & & & \multicolumn{2}{|l|}{$\begin{array}{l}0.45(0.21 \\
0.94)\end{array}$} \\
\hline \multirow[t]{4}{*}{ Employment status } & \multirow{2}{*}{$\begin{array}{l}\text { Formally } \\
\text { employed }\end{array}$} & 1.00 (ref) & 0.008 & \multirow{3}{*}{$\begin{array}{l}1.00 \text { (ref) } \\
0.94(0.73 \\
1.21)\end{array}$} & 0.620 \\
\hline & & $0.68(0.52,0.91)$ & 0.026 & & \multirow[t]{3}{*}{0.024} \\
\hline & $\begin{array}{l}\text { Self } \\
\text { employed }\end{array}$ & $0.66(0.45,0.95)$ & & & \\
\hline & Unemployed & & & $\begin{array}{l}0.63(0.42 \\
0.94)\end{array}$ & \\
\hline \multirow[t]{5}{*}{ Parity } & $1-2$ & 1.00 (ref) & 0.891 & 1.00 (ref) & 0.003 \\
\hline & $3-4$ & $1.02(0.77,1.36)$ & 0.044 & \multirow{2}{*}{$\begin{array}{l}1.48(1.14 \\
1.92)\end{array}$} & 0.201 \\
\hline & $5-6$ & $0.64(0.41,0.99)$ & \multirow[t]{3}{*}{0.229} & & \multirow[t]{3}{*}{0.354} \\
\hline & None & $0.67(0.34,1.29)$ & & $2.08)$ & \\
\hline & & & & $\begin{array}{l}1.43(0.67 \\
3.05)\end{array}$ & \\
\hline \multirow[t]{2}{*}{ Discuss FP with partner } & Yes & 1.00 (ref) & \multirow[t]{2}{*}{0.000} & 1.00 (ref) & \multirow[t]{2}{*}{0.000} \\
\hline & No & $0.28(0.21,0.36)$ & & $\begin{array}{l}0.39(0.29 \\
0.52)\end{array}$ & \\
\hline \multirow{2}{*}{$\begin{array}{l}\text { FP counselling provided at } \\
\text { the facility }\end{array}$} & Yes & 1.00 (ref) & \multirow[t]{2}{*}{0.000} & 1.00 (ref) & \multirow[t]{2}{*}{0.022} \\
\hline & No & $0.34(0.20,0.56)$ & & $\begin{array}{l}0.56(0.34 \\
0.92)\end{array}$ & \\
\hline
\end{tabular}

\section{Discussion}


Despite the calls for the need to urgently strengthen reproductive health services after the DTG teratogenicity alert, uptake of contraceptives was still low in our sampled population. The overall level of uptake of contraceptives for this study was $38.4 \%$ and uptake of modern contraceptives among the women using contraceptives was $37.9 \%$. Our findings were similar to the results of the $2016 \mathrm{Uganda}$ Demographic Health Survey (UDHS) that reported a contraceptive prevalence rate of $39 \%$ (5). However, findings from other SSA countries, found a higher contraceptive use among HIV-positive women, at $44.3 \%$ in Ethiopia (15), 46.4\% in Cameroon, (16), and 42.6\% in Ghana (17). The low level of contraceptive uptake in our study could be attributed to the fact that a high proportion of women were reportedly not sexually active and the program of switching to DTG regimens prioritized women aged above 40 years.

Injectable hormonal methods were the most used FP method in this study similar to the general population results of the 2016 UDHS report (5). This could be explained by the fact that women want short-term reversible methods, due to their reversibility and convenience (15).

Similar to other settings, we found that older participants (40-49 years) were less likely to use contraception than those of 15-24 years, most likely because they were less sexually active and they perceive themselves as less risky of conceiving (18).

Unemployed women were less likely to use contraception than those who were formally employed. Similarly, data from 21 African countries have shown that wealth is positively associated with contraceptive use due to access to private services (19). Women who had 3-4 children in this study were also more likely to use contraception than the ones with 1-2 children as previously reported.

A high proportion of women did not discuss FP methods with their partners, and they were less likely to use FP in the study. Previous studies demonstrated that partner contribution and approval of FP positively foster contraceptive use among women (20) (21).

In our study, the participants who did not receive FP counseling were less likely to FP use than those who received FP counseling. FP counseling positively affects the attitude to FP use and reduction of myths and misconceptions (22). When disseminating information on DTG use at HIV caregiving facilities, participants have a chance to express freely and inquire more about reasons for contraceptive use.

This study contributes to the understanding of the uptake of contraceptives among HIV-positive women in Uganda, by identifying the factors affecting contraceptive use in this population. It also contributes to the data on DTG use among women of reproductive age, as we scale up DTG based regimens. Programs should plan and integrate FP counseling and male involvement in reproductive health and HIV care programs.

The major strength of this study is that; it was carried out in five health centers across Kampala. In addition, the study sample of 359 women was adequate to power the study. Therefore, the data obtained from this study is fairly representable and generalizable to the general urban population. 
The main limitation of the study was social desirability bias where some participants could have given responses in a favorable manner fearing negative evaluations.

In conclusion, contraceptive uptake in this study was low and majority of the women were using injectable methods. The factors that increased the likelihood of contraceptive use were the age of respondents, employment status, parity, discussion of FP with a partner, and FP counseling.

We recommend that HIV programs should promote and offer FP counseling, and where feasible integrate FP services in HIV care. Women should also be encouraged to discuss FP choices with their partners or attend their ART visits with them.

\section{Abbreviations}

ART: $\quad$ Anti-Retroviral Therapy

CPR: $\quad$ Contraceptive Prevalence Rate

DTG: Dolutegravir

DMPA: Depot medroxyprogesterone acetate

EFV: $\quad$ Efavirenz

eMTCT: Elimination of Mother to Child Transmission

FP: $\quad$ Family Planning

HC: $\quad$ Health Centre

HIV/AIDS: Human Immunodeficiency Virus / Acquired Immunodeficiency Syndrome

IDI: Infectious Disease Institute

IRB: $\quad$ Institutional Review Board

IUD: Intrauterine Device

KCCA: Kampala Capital City Authority

LMIC: $\quad$ Low and Middle-Income Countries

mCPR modern Contraceptive Prevalence Rate

$\mathrm{MOH}: \quad$ Ministry of Health

MTCT: $\quad$ Mother to Child Transmission 
SD: $\quad$ Standard Deviation

UDHS: $\quad$ Uganda Demographic Health Survey

UNFPA: $\quad$ United Nations Fund for Population Activities

UNICEF: United Nations Children's Fund

WHO: $\quad$ World Health Organization

\section{Declarations}

\section{Ethics approval}

This study was approved by Makerere University Institute of Public Health Higher Degrees Research and Ethics Committee (HDREC), number 2016/HD07/2321U and Uganda National Council of Science and Technology (UNCST) number HS406ES. Written informed consent was obtained from each participant before any study activity and assent was obtained from the participants below 18 years of age. We also obtained written informed consent from parents or legal representatives of the minors. This study was carried out in accordance to the applicable ethical guidelines and regulations.

\section{Consent for publication}

This does not apply to this study.

\section{Data availability}

The datasets generated and analyzed during this study are not publicly available due to the strict data sharing policy of Infectious Diseases Institute. However, they are available from the corresponding author on reasonable request.

\section{Competing interests}

The authors declare that they have no competing interests.

\section{Funding}

Author BC is partly supported by the Fogarty International Centre, National Institute of Health (grant\# 2D43TW009771-06 "HIV and co-infections in Uganda"). 


\section{Author contributions}

L.M, S.K and J.K conceptualized the study and conducted the literature review. L.M, S.K, J.K, S.O, and B.C prepared the study protocol. L.M carried out data collection. L.M and M.S.N analyzed the data and wrote the manuscript. B.C, S.O, S.K, A.K, E.L, and M.L reviewed the manuscript. All the authors read and approved the final manuscript.

\section{Acknowledgments}

We would like to acknowledge the leadership of IDI and KCCA for allowing us to carry out this study and the lecturers of Makerere University School of Public Health for their guidance.

\section{References}

1. UNAIDS. Global HIV \& AIDS statistics - Fact sheet. Geneva, Switzerland: UNAIDS; 2021.

2. MOH. UGANDA POPULATION-BASED HIV IMPACT ASSESSMENT. Kampala: Ministry of Health Uganda, ICAP Columbia University; 2018.

3. Darroch JE, Sully E, Biddlecom A. Adding It Up: Investing in Contraception and Maternal and Newborn Health, 2017. Washington DC and Newyork City: The Guttmacher Institute, United Nations Populations Fund (UNFPA); 2017.

4. Napyo A, Nankabirwa V, Mukunya D, Tumuhamye J, Ndeezi G, Arach AAO, et al. Prevalence and predictors for unintended pregnancy among HIV-infected pregnant women in Lira, Northern Uganda: a cross-sectional study. Scientific Reports. 2020;10(1):16319.

5. UBOS la. Uganda Demographic Health Survey 2016. Kampala, Uganda and Rockville, Maryland, USA: Uganda Bureau Of Statistics (UBOS); 2018.

6. Avert. www.avert.org. Global Information and education on HIV and AIDS2018.

7. Wanyenze RK, Wagner G, Tumwesigye N, Nannyonga M, Wabwire-Mangen F, Kamya M. Fertility and contraceptive decision-making and support for HIV infected individuals: Client and provider experiences and perceptions at two HIV clinics in Uganda. BMC public health. 2013;13:98.

8. Milanga M, Rutter L. DOLUTEGRAVIR IN SOUTHERN \& EASTERN AFRICA AND THE RIGHT TO CHOOSE- POLICY BRIEFING. South Africa and Kenya: HealthGAP; 2018.

9. WHO. Statement on DTG. Geneva: World Health Organisation (WHO); 2018. Report No.: 1.

10. Dorward J, Hamers R. Dolutegravir in sub-Saharan Africa: context is crucial. The Lancet HIV. 2018;6.

11. WHO. Updated recommendations on first-line and second-line antiretroviral regimens and postexposure prophylaxis and recommendations on early infant diagnosis of HIV July 2018. Geneva: World Health Organization (WHO); 2018.

12. Nakkazi E. Changes to dolutegravir policy in several African countries. The Lancet. 2018;392(10143):3164-6. 
13. Chouchana L, Pariente A, Pannier E, Tsatsaris V, Treluyer J-M. Dolutegravir and neural tube defects: a new insight. The Lancet Infectious Diseases. 2020;20(4):405-6.

14. Bongomin F, Chelangat M, Eriatu A, Chan Onen B, Cheputyo P, Godmercy SA, et al. Prevalence and Factors Associated with Contraceptive Use among HIV-Infected Women of Reproductive Age Attending Infectious Disease Clinic at Gulu Regional Referral Hospital, Northern Uganda. BioMed Research International. 2018;2018:8.

15. Melaku A, Zeleke EG. Contraceptive Utilization and Associated Factors among HIV Positive Women on Chronic Follow Up Care in Tigray Region, Northern Ethiopia: A Cross Sectional Study. 2014;9(4):e94682.

16. Tsegaye R. Family planning need of people living with HIV/AIDS in antiretroviral therapy clinics of Horro Guduru Wollega zone, Ethiopia. BMC Research Notes. 2017;10(1):581.

17. Laryea $D$, Amoako Y, Spangenberg K, Kyei-Ansong J. Contraceptive use and unmet need for family planning among HIV positive women on antiretroviral therapy in Kumasi, Ghana. BMC women's health. 2014;14:126.

18. Abebe G, Nigatu R. Family planning service utilization in Mojo town, Ethiopia: A population based study. Journal of Geography and Regional Planning. 2011;4(6):355-63.

19. Elfstrom KM, Stephenson R. The Role of Place in Shaping Contraceptive Use among Women in Africa. PLOS ONE. 2012;7(7):e40670.

20. Shattuck D, Brad K, Kate G, Miriam H, Thokozani No, Guest G. Encouraging Contraceptive Uptake by Motivating Men to Communicate About Family Planning: The Malawi Male Motivator Project. American Journal of Public Health. 2011;101(6):1089-95.

21. Edietah EE, Njotang PN, Ajong AB, Essi MJ, Yakum MN, Mbu ER. Contraceptive use and determinants of unmet need for family planning; a cross sectional survey in the North West Region, Cameroon. BMC women's health. 2018;18(1):171.

22. Gueye A, Speizer IS, Corroon M, Okigbo CC. Belief in Family Planning Myths at the Individual and Community Levels and Modern Contraceptive Use in Urban Africa. Int Perspect Sex Reprod Health. 2015;41(4):191-9.

\section{Figures}




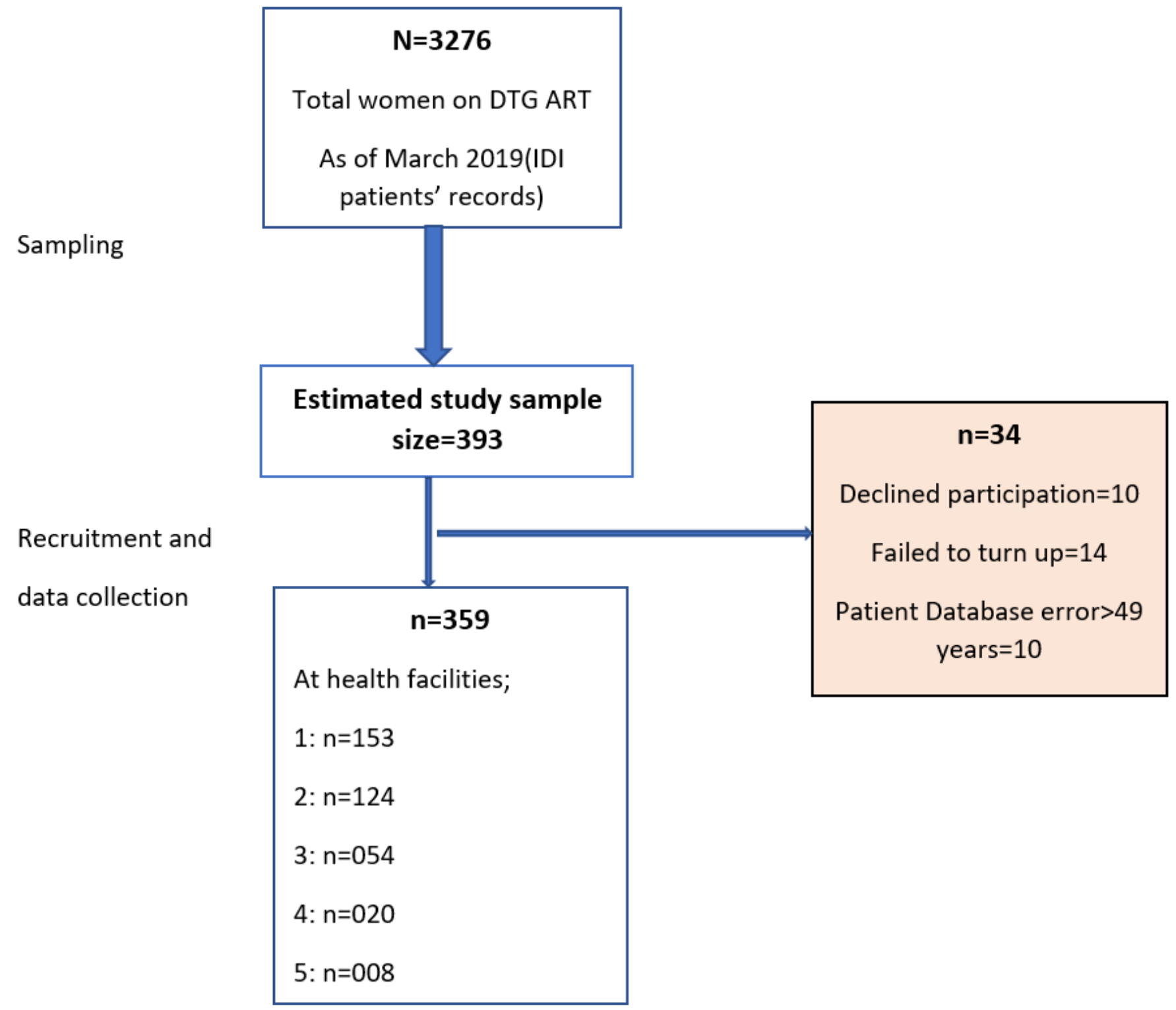

\section{Figure 1}

Three thousand two hundred and seventy-six women (3276) aged 15-49 years had been started or switched to DTG based ART regimen by March 2019. The sampling procedures are shown using the study flow diagram 


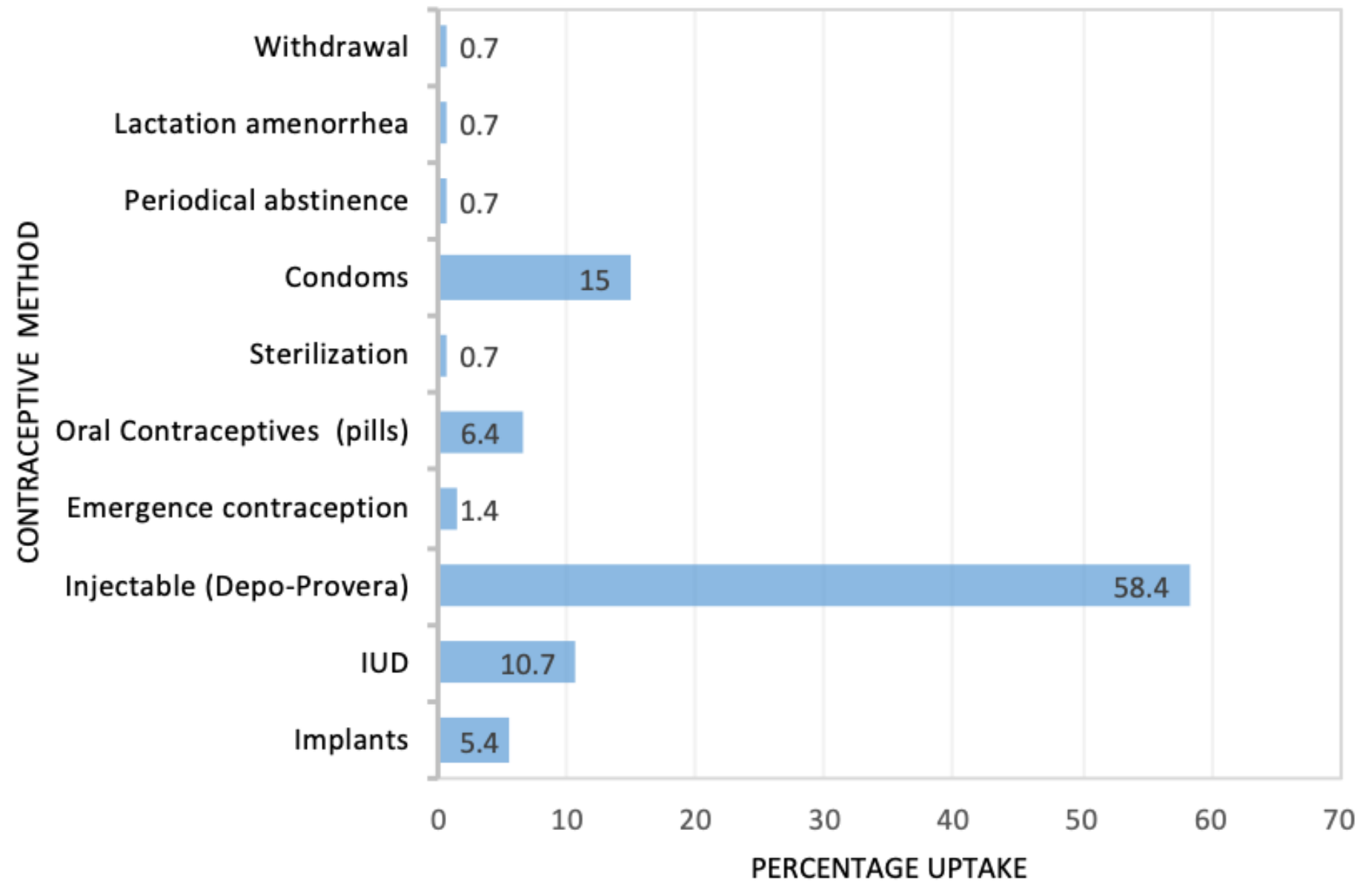

Figure 2

The different FP methods used by the respondents as of the time of the study 


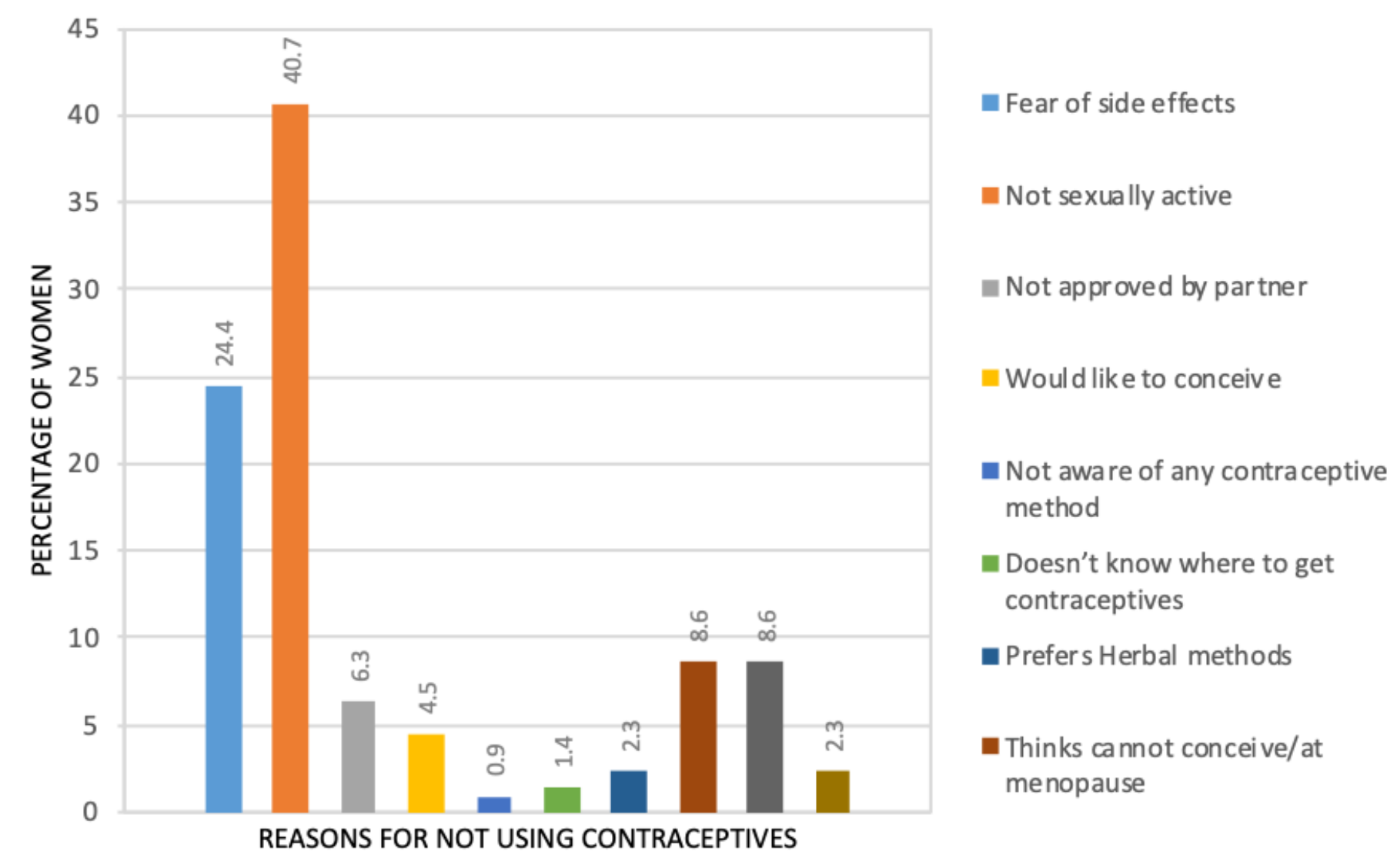

\section{Figure 3}

shows the different reasons women gave for not using contraceptives. 